\title{
CICLOS DE VIDA E ÉTICA DO ENVELHECIMENTO
}

\author{
CICLOS DE VIDA Y ÉTICA DEL ENVEJECIMIENTO
}

LIFE CYCLES AND ETHICS OF AGEING

Solange Aparecida de Souza MONTEIRO ${ }^{1}$

RESUMO: Neste estudo de natureza bibliográfica busca-se compreender a vivência do envelhecer. De escolhas vividas pelos sujeitos que estão envelhecendo, a saúde passa a ser essencial para a sua autonomia, o direito de encontrar significado para viver até a chamada terceira idade. O objetivo deste artigo é discutir e refletir as principais preocupações das pessoas com o envelhecimento, que consideram que com o envelhecimento perdem sua identidade, sentem ainda que não se identificam com sua idade cronológica e com fato de não se sentirem envelhecidas. Fundamentada nas contribuições de Foucault, em suas pesquisas genealógicas, pretende-se pensar o envelhecimento como uma escolha ética ligada a uma estética da existência e de saúde como uma dimensão da vida que não exclui a sexualidade a morte e a doença.

PALAVRAS-CHAVE: Envelhecimento humano. Ética. Sexualidade.

RESUMEN: Este estudio bibliográfico busca comprender la experiencia del envejecimiento. A partir de las elecciones vividas por los sujetos que están envejeciendo, la salud se vuelve esencial para su autonomía, el derecho a encontrar sentido para vivir hasta la llamada tercera edad. El objetivo de este artículo es discutir y reflejar las principales preocupaciones de las personas con el envejecimiento, que consideran que con el envejecimiento pierden su identidad, todavía sienten que no se identifican con su edad cronológica y con el hecho de que no se sienten Envejecido. Sobre la base de las aportaciones de Foucault, en sus investigaciones genealógicas, pretendemos pensar en el envejecimiento como una elección ética ligada a una estética de la existencia y de la salud como dimensión de vida que no excluye la sexualidad de la muerte y de las enfermedades.

PALABRAS CLAVE: Envejecimiento humano. Ética. Sexualidad.

ABSTRACT: This bibliographic study seeks to understand the experience of aging. From the choices lived by the subjects who are aging, health becomes essential for their autonomy, the right to find meaning to live until the so-called Third Age. The aim of this article is to discuss and reflect the main concerns of people with aging, who consider that with aging lose their identity, they still feel that they do not identify with their chronological age and with the fact that they do not feel Aged. Based on Foucault's contributions, in his genealogical researches,

${ }^{1}$ Instituto Federal de São Paulo (IFSP), Araraquara - SP - Brasil. Pedadoga. Mestra em Processos de Ensino, Gestão e Inovação pela Universidade de Araraquara - UNIARA (2018). Membro dos núcleos: -Núcleo de Gêneros e Sexualidade do IFSP (NUGS); Núcleo de Apoio às Pessoas com Necessidades Educacionais Específicas (NAPNE). ORCID: <http://orcid.org/0000-0002-1640-0266>. E-mail: solmonteiro@ifsp.edu.br 
we intend to think of aging as an ethical choice linked to an aesthetic of existence and health as a dimension of life that does not exclude sexuality from death and disease.

KEYWORDS: Human ageing. Ethics. Sexuality.

\section{Introdução}

A vida é um ciclo no qual o indivíduo é gerado, cresce, amadurece, envelhece e morre. A adaptação de cada uma dessas fases é um grande desafio para o homem, pois muitas vezes implica, no final da vida, a perda de autonomia e a mudança de sua condição humana.

De acordo com os dados do Instituto Brasileiro de Geografia e Estatística (IBGE, 2018) nos últimos 20 anos, as taxas de crescimento de idosos no Brasil vem crescendo progressivamente. Como causas deste aumento do número de idosos, podemos destacar a melhoria da qualidade de vida, até mesmo por possuírem novas prioridades, como a própria independência. Além disso, o acréscimo da população idosa está relacionado ao baixo índice de crescimento populacional ligado a menores taxas de fecundidade.

De acordo com Kalache (2007) "os países desenvolvidos primeiro enriqueceram e depois envelheceram. Países como o Brasil estão envelhecendo antes de serem ricos”. Nesse contexto é preciso analisar que as modificações se dão numa conjuntura nacional marcada por alta vulnerabilidade e desigualdade social, condições de extrema pobreza e de enfraquecimento das instituições.

Negri (2004) aborda que a condição de eternidade e das ações que seria o entendimento de uma existência e consciência coletiva, estaria além da própria morte de um indivíduo e seria um elo à ideia de que a morte ocorreria somente do corpo físico, porque a eternidade dos atos de um ser humano permanece viva, ou seja, num contínuo de "ser lembrado" mesmo após a morte.

Mercadante (1997, p. 2) salienta a importância de compreendermos a velhice como um fato natural e cultural: "É natural e, portanto, universal se apreendida como um fenômeno biológico, mas é também imediatamente um fato cultural na medida em que é revestida de conteúdos simbólicos, evidenciando formas diversas de ação e representação".

Com base nisso, para tratar a saúde do idoso, mesmo que com alguns desvios de saúde que esteja no corpo, é preciso considerar que esta é a última e mais enriquecida etapa da vida. $\mathrm{Na}$ escalada da vida, passamos por várias experiências tais como crescer e envelhecer, a fase da criança e adolescente, ou seja, a de brincar, estudar e crescer. A Etapa intermediaria, viver, envelhecendo na vida, trabalhar, constituir família e produzir. Elege-se sempre as prioridades 
para que ao aposentar-se, possa curtir a vida e ousar a viver, o processo de envelhecimento com experiências e sentimentos ampliados e misturados à aprendizagem que foram sendo construídos, por isso conhecer os interesses da população que envelhece a garantia de seus direitos e a viabilização de programas que sejam abertos à maioria é um ato imprescindível e de caráter social.

No entanto nem sempre a sexualidade do idoso é vista com naturalidade. Um idoso que expressa sua sexualidade de maneira espontânea, é visto como desviado, como se estivesse infringindo uma "lei de bom senso". Isso também acontece dentro do âmbito familiar, pois os filhos dificilmente admitem a necessidade sexual dos pais e, quando admitem, veem-na isso de maneira depreciativa (RIBEIRO, 2007).

Schirrmacher (2005) aponta que pela primeira vez na história da humanidade, o número de idosos será maior que o de crianças e jovens e pela primeira vez, o envelhecimento será um processo coletivo, uma vez que gerações compartilham esse envelhecer no mesmo tempo histórico.

O idoso é uma unidade social que, independente do envelhecimento traz transformação individual e coletiva para a sociedade. $\quad \mathrm{O}$ tema envelhecimento é ainda controverso, pois todos os processos da vitalidade humana experimentados desde o nascimento, a infância e a adolescência até a vida adulta persiste a negação quando elege e se compara aos padrões de beleza que adotado pelos jovens o não reconhecer que o envelhecimento não significa apenas a doença, solidão, privação, dependência, tristeza e frustração. Considerar que os movimentos de passagem de uma etapa do ciclo vital para outras são naturais e seguros. Na verdade, seria preciso uma mudança de cultura, começando desde a infância como um processo natural.

É preciso desenvolver novas estratégias que visem a levar a vida para o limite máximo da espécie humana. O relógio biológico da espécie humana atinge entre 90 e 95 anos, estes valores são aceitos por diversos pesquisadores, é bem provável que nas próximas décadas o relógio biológico seja ainda mais expandido, sendo assim é urgente criar uma nova cultura sobre o envelhecimento positiva como um tempo produtivo característico da vida, social emocional, intelectual e social, superando assim os estigmas da discriminação.

Segundo Debert (2003, p. 51) a velhice não é uma categoria natural, mas, como qualquer outra categoria de idade, é uma construção histórica e social. Para o autor, a velhice não é uma categoria natural, mas, como qualquer outra categoria de idade, é uma construção histórica e social. A construção de uma categoria social depende da elaboração simbólica de 
rituais que demarcam e definem espaços, demandas, comportamentos, direitos e deveres. Assim essa constituição identitária acontece de maneira complexa e plural para cada pessoa.

\section{O Envelhecer e a identidade social e pessoal}

A construção da identidade social e pessoal para viver o maior tempo possível como sujeitos sociais e garantirem que a velhice será abordada como um acontecimento da vida, um destino, mas, também, como um experimento, ou seja, a possibilidade de invenção de modos de existência que contrariem os modelos e valores vigentes na atualidade. $\mathrm{O}$ que permite pensar a velhice em termos de identidade social e perceber que ela é uma classificação, que há uma valoração por parte da sociedade e uma característica própria e autovaloração da idade etária, separando e agrupando os indivíduos em um parâmetro de idade.

Papaléo Netto (2002) aborda o tema envelhecimento de forma abrangente, incluindo a saúde, doença, tempo e morte, compreende necessária e principalmente a análise dos aspectos sociais, culturais, políticos e econômicos relativos a valores, estigmas e sistemas carregados de simbologias, que traçam a história das sociedades humanas e suas representações sociais. Envelhecer faz parte do processo humano que é inexorável e natural.

É importante a interação, a comunicação e a convivência com outros idosos buscandose não criar uma imagem de velhos, entendendo que os idosos são pessoas que vivem uma etapa da vida, e a produção de cada um segue seu curso, na sua área de conhecimento, quando ensinam, pesquisam ou produzem. É imprescindível que os idosos saibam reconhecer que cada um tem uma identidade singular e pessoal, cada um assumindo-se sem exigir de si a uniformidade. Os sujeitos independentes de sua idade têm papeis diferentes a desempenhar.

Torna-se, portanto, importante que a sociedade reveja seus conceitos e preconceitos sobre a sexualidade e entenda o quanto ainda é possível e necessária a troca afetiva que pode ser realizada por toda a vida do ser humano. Apesar das mudanças em algumas áreas para que os idosos possam não se sentir culpados pelos seus desejos sexuais, independentemente da forma de sua manifestação, os preconceitos em relação à atividade sexual precisam ser discutidos e analisados, visando a uma melhor explicação e orientação das verdadeiras mudanças existentes no seu comportamento sexual. (RISMAN, 2005)

Néri (2001) aponta que "a vida madura passa a ser um momento de culminância biológica, psicológica ou social do ciclo vital, em que o indivíduo exibe as estruturas ou os comportamentos esperados para a sua idade”. Desta forma, essa estruturação do indivíduo na velhice representa o seu tempo subjetivo de ser sujeito de si, em modelar, direcionar e dizer 
qual o espaço e lugar de fala que deseja ocupar, quais as condições para algumas transposições de dificuldades, o que deve aceitar ou rejeitar os desenhos de vida que quer construir como prioridade para viver melhor o seu tempo. Este reconhecimento de si e sua assimilação, faz com que o homem tente viver em sua subjetividade temporal, não abrindo os seus avessos, mostrando uma suposta assimilação do que ainda parece ser seu e o tempo subjetivo e a natureza de poder fazer suas atividades cotidianas ao reconquistar as experiências de vida no mundo possível, armazenadas em suas memórias, ou em uma outra perspectiva, que "lute garridamente para conseguir ser visto na invisibilidade que a sociedade impõe ao velho.”. (LOUREIRO, 2005)

Para Almeida (2005, p. 55), "a identidade é um processo social porque o conhecimento de alguém se dá no (re)conhecimento recíproco dos indivíduos nos grupos, nas instituições, na sociedade de que fazem parte". Ele argumenta que é "social também porque ela é constituída nos e pelos grupos de que os indivíduos fazem parte, pelos papéis sociais (formais e não-formais) que eles desempenham e pelo modo como desempenham” (p. 56).

A identidade, segundo Almeida (2005, p. 58), “expressa um processo dinâmico de articulação entre o fazer-se e pensar-se, o representar-se e buscar reconhecimento, de um lado e o ser produzido, representado e reconhecido socialmente, por outro lado".

\section{Ética do cuidado humano}

Por escolha ética entende-se, de acordo com Foucault (2006), uma maneira de relação consigo independente dos códigos morais de conduta formalizados ou não em leis prescritas por instâncias externas religiosas ou civis que assumem um caráter universal. Considera-se o processo de constituição do próprio sujeito ético, pelas práticas de si.

Ao afirmar-se com o relacionamento de si consigo, em que o sujeito se auto constitui, advém de uma compreensão teleológica de algo que se considera natural ou como um processo de conhecimento de si a fim de descobrir uma verdade no sujeito; o cuidado de si.

A relação do sujeito com a verdade, de acordo com Foucault (2006), pode dar-se pelas práticas de sujeição ou práticas de liberdade. No primeiro, o autor aponta que o sujeito é produto objetivo de relações de poder e de regimes de verdade que individualiza segundo as exigências do poder e liga cada individualidade a uma identidade reconhecida por cada um e por todos, o sujeito velho. Esse sujeito, quando analisado fundamentada na instituição política, só poderá ser afrontado numa dimensão jurídica como sujeito de direito. Em segundo, o sujeito se constitui a si mesmo em um jogo aberto e livre nas escolhas de sua 
existência, por meio de suas práticas em relação a si e aos outros. É um modo de subjetivação e não de uma sujeição. A escolha livre de seu modo de existência configura o sujeito ético. Uma ética do envelhecimento deverá levar em consideração o modo existência e o de subjetivação

Para Carvalho Filho (1994), o envelhecimento está sujeito a características singulares, porque esse processo ocorre em cada indivíduo de uma forma, ou seja, dinâmica e frequente, com alterações na morfologia e na funcionalidade, de forma bioquímica e psicológica, que poderão ter implicações desde a perda da capacidade de adaptação ao meio em que vive, onde observamos inúmeras fragilidades, como queda da resistência imunológica um fator de maior incidência e constância, de qualquer sofrimento emocional ou físico que possa aparecer e de processos patológicos, fatores esses comuns para esta fase da vida, e que acabam levando-o à morte.

Essa velhice que Foucault (2010), fundado em Sêneca, aproxima e é observada é tanto uma velhice cronológica que começa por volta dos 60 anos, como é também uma velhice ideal: "uma velhice que, de certo modo, fabricamos; uma velhice para o qual nos preparamos" (p. 137). O ponto principal dessa "nova ética da velhice" consiste em colocar-se em relação à vida em uma situação sistêmica em que se vive como se a tivesse consumado. Esse caráter ético em relação à vida deve ser praticado mesmo quando se é jovem: "consumar a vida antes da morte".

Diniz e Medeiros (2004), apontam que “A questão moral a enfrentar, portanto, não se resume a uma interpretação de quais são as idades que definem as etapas do ciclo "natural" da vida, ou, na fronteira, qual é a idade a partir do qual se assume que a vida pode ou deve terminar para liberar saídas do sistema de saúde, mas que tipo de vida o sistema de saúde deve proteger" incidência de processos patológicos que terminam por leva-lo à morte.

Tótora (2006) aponta que o velho, nessa relação de poder e de saber, dispõe de um corpo alvo de controle de uma ciência à qual se atribui a meta de prolongar a vida, evitando a morte. Os profissionais do saber arvoram-se, muitas vezes, em condutores do modo de se viver, instituindo nos viventes a cultura pelos malefícios que venham a sofrer. Na pretensão de dirigir a vida, controlando o seu processo, com o intuito de melhorá-la, multiplicam-se as prescrições a serem seguidas como modelos gerais.

Foucault (2010) revela que a velhice como uma das áreas de intervenção da biopolítica de que versa nessa nova tecnologia do poder, nessa biopolítica, em um biopoder que está se alojado. O conjunto de processos como a produção dos nascimentos, dos óbitos, a taxa de reprodução, a fecundidade de uma população, etc. São esses processos de natalidade, de 
mortalidade, de longevidade que, justamente na segunda metade do século XVIII, ao lado com uma quantidade de problemas econômicos e políticos e principais objetos de saber e as primeiras conotações de controle dessa biopolítica.

O envelhecimento se estabeleceu de outra forma nas sociedades contemporâneas. O idoso apresenta-se mais livre de situações em que possa sentir-se constrangido, ameaçado, humilhado, ele sente-se mais preparado para adversidades e ocorrências do cotidiano depreciativas, ele não se expõe aos interesses do mercado de consumo que submerge que se organiza, principalmente, com atividades de lazer e de saúde adequados. Há uma modificação no panorama, onde a ausência de produtividade em decorrência do tempo de trabalho e com a chegada da aposentadoria ocorre uma alteração desencadeada por meio da inserção do idoso em uma exposição exacerbada pelo consumo, sendo também um interesse e público alvo para o mercado, abrindo-se um nicho de comércio rentável. A jovialidade, o vigor, a produtividade conquistada a velhice é acolhida dentro de grande agenda que envolve medicamentos, moradia adaptada e condicionadas, a segurança, conforto, inserindo a indústria farmacêutica, ou seja, medicamentos e exercícios corretos e o consumo de tudo quanto potencialize a juventude eterna.

Se tornando corpos dóceis úteis, esses cidadãos são capturados por serviços e produtos de todos os tipos, como grupos de atividades físicas, de turismo, universidades para terceira idade, praças públicas com diversos equipamentos destinados à "melhor idade", cosméticos exclusivos para esta faixa etária, vestuário específico, cirurgias plásticas. Implicados nestes discursos dominantes, os idosos viram o jogo e são agora criados investimentos biopolíticos para o controle social desta população.

Segundo Debert (2012), o termo tem diferentes abordagens, pode ser entendido como decadente, frustrado, vulnerável, algo que não é mais útil, todo esse julgamento passa a ideia de oposição entre velho antiquado inútil e jovem inovador util. Já a palavra "idoso" recebe um significado menos nocivo, referindo-se apenas a um indivíduo que possui anos de vivência.

A definição da velhice é algo inacabado, os domínios que o idoso está sujeito e vive socialmente e constrói uma identidade que considera a sua adaptação a essa nova identidade cultural em que o idoso estiver inserido adaptar. Sendo a identidade uma característica própria da sua natureza humana que uma continuamente na tentativa de um ideal e de uma característica inerente, mesmo sendo algo inconstante e mutável, não é algo acabado. A identidade se transforma com a passagem do tempo e de acordo com o conjunto na qual está inserida, do relacionamento um com outro, assim permanece essa busca incessante de identidade para edificar uma história que nos difere uns dos outros (HALL, 2006). 
Pascual (2002) postula que existe, em nossa sociedade um conceito de velhice desgastado e negativado, notadamente na esfera sexual. Os profissionais da saúde devem apoiar e buscar formação e assim ao mesmo tempo. Os profissionais de saúde e os familiares não podem ser barreiras para que os idosos sejam sexualmente ativos.

Além disso, os meios de comunicação proporcionam uma visão pouco atrativa do processo de envelhecimento e, consequentemente, da pessoa idosa. Essa situação é extremamente prejudicial aos idosos, tendo em vista que a sexualidade é essencial para qualidade de vida, eficaz para manter as relações interpessoais saudáveis. Está ligada a s autoestima e não pode ser anulada, negada que por sua vez pode não apenas trazer a sexualidade em si, mas também em uma autoimagem distorcida, relações sociais e saúde mental.

O processo de envelhecimento não leva a uma fase assexuada, mas à outra fase do processo da sexualidade humana, que deve ser vivida e valorizada corretamente (FÁVERO; BARBOSA, 2011). As experiências sexuais, independentemente da idade, oferecem aos casais a oportunidade de se desenvolverem pessoalmente, refletirem intimidade e cumplicidade e enriquecerem as relações humanas.

Para os idosos, a sexualidade é fisiologicamente possível, emocional e afetivamente enriquecedora, pois fortalece a importância do afeto, apego, comunicação, companheirismo e cuidado mútuo (URQUIZA et al., 2008). O tempo não dessexualiza a pessoa mais velha, uma vez que a sexualidade está presente em todas as fases da vida, passa por "uma maneira de fazer e refazer, um caminho instável, em constante transformação, assim como as pessoas, uma parte inseparável deles". (PIRES, 2006, p. 2)

Segundo Butler e Lewis (1985), o sexo e a sexualidade são experiências prazerosas, gratificantes e reconfortantes. Afeto, calor e sensualidade não precisam se deteriorar com a terceira idade e, na verdade, podem até mesmo aumentar. O sexo na terceira idade é o sexo por si mesmo: prazer, liberação de tensão, comunicação, intimidade compartilhada. O sexo ativo prova para as pessoas de mais idade que seus corpos ainda são capazes de funcionar bem, de causar e dar prazer.

No decorrer do envelhecimento, a sexualidade modifica tanto quanto os outros comportamentos, mas isso não implica necessariamente uma redução drástica da resposta sexual, pois depende fundamentalmente da atitude que cada pessoa adota antes da vida. Ocorre de forma extremamente individual e não se desdobra da mesma forma em cada momento, nem mesmo da mesma forma em todos os indivíduos. (PASCUAL, 2002) 
A crença de que o envelhecimento e a ausência de experiências sexuais estão inextricavelmente ligados é errônea e contribui de alguma forma para a falta de conhecimento e preconceito sobre a sexualidade do idoso, o que, consequentemente, compromete a qualidade de vida do idoso. (VIEIRA, 2012)

Devido à falta de conhecimento e pressão cultural, muitas pessoas mais velhas que ainda têm um desejo sexual latente às vezes experimentam culpa e vergonha, simplesmente porque se percebem ansiosas em buscar prazer. Esses comportamentos criados pela sociedade limitam a sexualidade humana ao período da juventude e, portanto, não são reforçados pela sociedade aos idosos. Pelo contrário, os idosos são frequentemente vítimas de preconceito, o que afeta muito sua qualidade de vida.

A partir do desconhecido e da pressão cultural, muitos idosos que ainda possuem desejo sexual, às vezes experimentam sentimento de culpa e vergonha, simplesmente percebendo-se com o desejo de buscar prazer. Esses padrões de comportamento criados pela sociedade limitam a sexualidade humana ao período da juventude, por isso não são reforçados pela sociedade na velhice. Pelo contrário, o idoso é frequentemente vítima de preconceito, o que causa grande perda de qualidade de vida.

No que se refere à sexualidade, ainda hoje, dois problemas são verificados na abordagem dessa questão no momento do cuidado do idoso. Por um lado, o profissional de saúde tem muitas vezes vergonha de fazer perguntas sexuais a idosos, dada a investigação desrespeitosa. Por outro lado, os idosos sentem-se envergonhados e não têm a coragem de fazer perguntas aos profissionais porque tem medo de ser mal compreendido. (VIEIRA, 2012)

De acordo com Viana e Madruga (2010), o idoso deve se sentir confortável para expressar emoções e necessidades, sem ficar temeroso ou envergonhado ao discutir problemas a respeito da sexualidade. Por outro lado, os profissionais de saúde devem ser isentos de preconceitos, falar diretamente sobre o assunto, responder a todas as questões, sem rodeios ou constrangimentos, mostrar que querem e precisam discutir o tema, com interesse, e mostrar dados científicos sobre alguns assuntos e casos.

O idoso entendendo que a atividade sexual é prazerosa, podendo ser esclarecida através dos discursos que a sexualidade é prazer, é a satisfação do prazer, sexualidade é a busca do prazer, é uma coisa muito prazerosa, é o prazer que sentimos em estar com o outro. A sexualidade não se extingue mais pela velhice, é possível a manutenção da atividade sexual em todas as fases da vida, proporcionando bem-estar e qualidade de vida aos idosos

Segundo Bruns (1996), a sexualidade, mesmo que não admitida conscientemente, revela sua verdadeira face. É na sexualidade de cada um que está impressa e expressa a 
história pessoal, bem como o modo de lidar com a trajetória do envelhecimento, aprendendo como lidar com essa incontrolável realidade, que é o envelhecimento humano.

Desta forma, a desmistificação do sexo na velhice é de fundamental importância, e são equívocos que dificultam que os idosos aproveitem essa etapa de uma vida melhor no que diz respeito ao campo afetivo e sexual. É verdade que, com o envelhecimento, transformações fisiológicas em homens e mulheres são produzidas, mas não seus inibidores da atividade sexual, como a capacidade de amar para as práticas sexuais não têm limite cronológico o limite está no campo psicológico, no preconceito na intolerância social.

Por fim, para Vicente (2005), a sexualidade é vista como uma característica humana que não se perde com o tempo, mas se vai desenhando conforme a história vivenciada pelo corpo vivente em sua trajetória existencial. Fica explícito pelo exposto que a sexualidade não se limita apenas à reação aos estímulos eróticos; ela ultrapassa o ato sexual, uma vez que inclui o amor, o carinho, a troca de palavra, o toque, o compartilhar entre as pessoas que se expressam e se percebem como homens ou mulheres, independentemente da imagem apresentada, da "tatuagem" feita pela postura, pelo tempo e apresentada pelo cabelo grisalho, pelas rugas e outras alterações decorrentes do processo de envelhecimento.

\section{O processo de erotização da velhice}

O envelhecimento ocorre de maneira singular e complexa e não representa sinônimo de incapacidade funcional, vício ou falta de experiências sociais e sexuais. Mesmo em caso de perdas, é possível viver uma velhice de sucesso.

A velhice, como um período de declínio sexual inevitável e universal, representa um padrão interpretativo básico que marcou a história do pensamento sobre o envelhecimento e que, segundo Katz e Marshall (2003), moldou a expectativa de que os indivíduos devem se adaptar a esse imperativo, a fim de colher os benefícios morais da maturidade pós-sexual.

A sabedoria do século XIX postulava que um modo cauteloso de vida deveria tentar retardar esse declínio, mas aceitá-lo era parte do exercício moral de adaptação aos efeitos do processo de envelhecimento. No entanto, como mostram esses autores, a associação entre o rejuvenescimento e a restauração das funções sexuais já estava presente nos anúncios de poções e terapias, que foram posteriormente considerados como práticas charlatãs ou de má reputação.

A sexualidade na velhice instaura uma nova ordem no desenho do debate dos especialistas sobre o envelhecimento saudável. O desenvolvimento de novas tecnologias e 
argumentações empregadas para sustentar a viabilidade de uma erotização da velhice estão diretamente ligadas a políticas e programas em diferentes partes do mundo de um modelo de envelhecimento mais ativo da saúde sexual.

O bem-estar subjetivo na velhice na experimentação do prazer proposta aos idosos estão subordinados organização individual do envelhecimento de acordo com as normas da vida contemporâneas que coloca em evidencia a vida saudável como um critério para ser sexualmente adequado.

A cultura do envelhecimento vem sendo reinventada e explorada, refletindo na relação experiências diferentes, crenças e atitudes. O sexo na idade madura nem sempre vem da relação com o outro por amor, carinho, companheirismo esta cultura acontecia em relações antigas que cresceram e se desenvolveram através dos anos, os relacionamentos desenvolveram e evoluíram na idade madura, e novas relações como e modos de existência de se viver a sexualidade surgem. $\mathrm{O}$ sexo para as pessoas da terceira idade pode revelar que seus corpos ainda são ativos e capazes de relacionar e funcionar bem e ainda trazer prazer,

A vida é sempre uma continuidade e a sexualidade, permanece como um dos limites, quando nascemos o nosso coração bate e a respiração acontece e assim as emoções e ações orgânicas relacionadas a sexualidade também existe desde o início e vai nos acompanhar até o nosso fim de vida, como seres humanos, de maneira mais intensa em algumas situações e menos intensas em outras e a reflexão de que a sexualidade no idoso mostra-se um desafio para educadores sexuais, para os profissionais de saúde é uma área de extensa investigação e de aprofundamento cientifico.

De acordo com Bruns (1996), a sexualidade, mesmo que não admitida conscientemente e, revela o que somos. E o que somos traz em si o que já fomos, e a possibilidade de vir a ser. É na sexualidade de cada um que está impressa e expressa a história pessoal, bem como o modo de lidar com a trajetória do envelhecimento, aprendendo como lidar com essa incontrolável realidade que é o envelhecimento humano.

Para Hogan (1985), a sexualidade deve ser compreendida como intrínseca a todo o indivíduo, a qualquer momento de sua vida, considerada singular a cada pessoa. A sexualidade é a fusão de sentimentos simbólicos e físicos, como ternura, respeito, aceitação e prazer. É construída progressivamente, sendo influenciada pela história, pela sociedade e pela cultura, conforme os aspectos individuais e psíquicos de cada um.

\section{Considerações finais}


Ao terminar este artigo sinto que muitos estudos a acerca do envelhecimento precisam ser produzidas, com novos olhares, pesquisar as condições e as necessidades emergentes para a população de idosa. A condição da velhice e da terceira idade como identidades estão fortemente ligadas a fatos históricos, conhecimentos médicos e sociais, movimentos políticos e interesses que as qualificam e robustecem a formação tanto da velhice é necessário construirmos novos conhecimentos, explicitar que somos favoráveis aos novos conhecimentos, novas culturas que podem trazer novos contornos como sujeitos ativos, que pretende alcançar novos fragmentos alguns fragmentos do percurso histórico balança nossas certezas sobre esse campo do conhecimento que são marcados por discursos compostos de verdades de cada tempo e lugar, enquanto sujeitos de saber e sujeitos de poder na atualidade, provoca o nosso pensamento para discutirmos a história de maneira diferente do que se pensa para refletir-se diferente do que se tornou.

Neste sentido é importante que os profissionais de saúde estejam preparados para questionar sobre a vida sexual dos idosos, para que se sintam confiantes e possam receber orientação, lançando luz a sua qualidade de vida.

Em vista do exposto, restam algumas perguntas: Não seria a velhice um momento privilegiado para experimentar a grande saúde? A sabedoria da velhice é o resultado de um longo processo de cuidado de si.

\section{REFERÊNCIAS}

ALMEIDA, J. A. M. Sobre a anamorfose: identidade e emancipação na velhice. Tese (Doutorado em Psicologia Social). Pontifícia Universidade Católica de São Paulo, São Paulo, 2005.

BRUNS, M. T. Envelhecimento: essa incontrolável realidade humana. Revista Viver

Psicologia. Rio de Janeiro, n. 43, p. 11-13, maio/jun. 1996.

BUTLER, R. N.; LEWIS, M. L. Sexo e amor na terceira idade. São Paulo: Summus, 1985.

CARVALHO FILHO, E. T.; ALENCAR, Y. M. G. Teoria do envelhecimento. In: CARVALHO FILHO, E. T (Org.). Geriatria. fundamentos, clínica, terapêutica. São Paulo: Atheneu, 1994, p. 1-8.

DEBERT, G. G. A reinvenção da velhice. São Paulo: Edusp/Fapesp, 2003.

DUARTE, L. F. D. A sexualidade nas ciências sociais: leitura crítica das convenções. In: PISCITELLI, A. et al. Sexualidades e saberes, convenções e fronteiras. Rio de Janeiro: Garamond, 2004, p. 39-81. 
FÁVERO, M. F.; BARBOSA, S. C. S. Sexualidade na velhice: os conhecimentos e as atitudes dos profissionais de saúde. Terapia Sexual, v. 14, n. 2, p. 11-39, 2011.

FOUCAULT, M. Hermenêutica do sujeito. Trad. de Márcio Alves da Fonseca e Salma Tannus Muchail. São Paulo: Martins Fontes, 2004.

FOUCAULT, M. Microfísica do poder. 9. ed. Rio de Janeiro: Graal, 2010.

HALL, S. A identidade cultural na pós-modernidade. Tradução de Tomaz Tadeu da Silva. 11. ed. Rio de Janeiro: DPeA, 2006.

INSTITUTO BRASILEIRO DE GEOGRAFI A E ESTATÍSTICA (IGBE). Número de idosos cresce $18 \%$ em 5 anos e ultrapassa 30 milhões em 2017. Agência IBGE de Notícias, Rio de Janeiro, 2018. Disponível em: https://agenciadenoticias.ibge.gov.br/agencianoticias/2012-agencia-de-noticias/noticias/20980-numero-de-idosos-cresce-18-em-5-anos-eultrapassa-30-milhoes-em-2017. Acesso em: 14 dez. 2018.

KALACHE, A. Envelhecimento populacional e as informações de saúde da PNAD: demandas e desafios contemporâneos. (Posfácio). Cadernos de Saúde Pública, Rio de Janeiro, v. 23, n. 10, p. 2503-2505, 2007.

KATZ, S.; MARSHALL, B. New sex for old: lifestyle, consumerism, and the ethics of aging well. Journal of Aging Studies, v. 17, n. 1, p. 3-16, 2003.

LOUREIRO, A. M. L. Historicidade e tempo na velhice como reflexo da história de vida. In: ANAIS do Congresso Brasileiro de Geriatria e Gerontologia. Goiânia, 2006.

NEGRI, L. S. A. et al. Aplicação de um instrumento para detecção precoce e previsibilidade de agravos na população idosa. Ciência \& Saúde Coletiva, v. 9, p. 1033-1046, 2001.

MEDEIROS, M.; DINIZ, D. Envelhecimento e deficiência. In: CAMARANO, A. A. (Org.). Os novos idosos brasileiros: muito além dos 60? Rio de Janeiro: IPEA, 2004, p. 107-120.

MERCADANTE, E. F. A Construção da Identidade e da Subjetividade do Idoso. Tese (Doutorado em Ciências Sociais). Pontifícia Universidade Católica de São Paulo, São Paulo, 1997.

MORAES, M. et al. Velhice ou terceira idade? Rio de Janeiro: Fundação Getúlio Vargas, 1998, p. 69-84.

NÉRI, A. L. Palavras-chave em gerontologia. Campinas: Alínea, 2005a.

NÉRI, A. L.; FREIRE, S. A. E por falar em boa velhice. Campinas: Papirus, 2005.

PAPALÉO NETTO, M. Envelhecimento: desafio na transição do século. In: PAPALÉO NETTO, M. et al. Gerontologia - a velhice e o envelhecimento em visão globalizada. São Paulo (SP): Atheneu, 1996. 
PAPALÉO NETTO, M. O estudo da velhice no século XX: histórico, definição do campo e termos básicos. In: FREITAS, E. et al. (orgs.). Tratado de geriatria e gerontologia. Rio de Janeiro: Guanabara Kroogan, p. 2-12, 2002.

PASCUAL, C. P. A sexualidade do idoso vista com novo olhar. São Paulo: Loyola, 2002.

PIRES, R. C. C. A. Sexualidade feminina, envelhecimento e educação: algumas aproximações necessárias. Revista UDESC, v.7, n. 1, p. 1-7, 2006.

RIBEIRO, A. Sexualidade na terceira idade. In: PAPALÉO NETTO, M. Tratado de gerontologia. 2. ed. rev. e ampl. São Paulo: Atheneu, 2007. cap. 23, p. 279-292.

RISMAN, A. Sexualidade e terceira idade: uma visão histórico-cultural. Textos sobre envelhecimento, Rio de Janeiro, v. 8, n.1, 2005. Disponível em: Acesso em: 27 maio 2010.

SCHIRRMACHER, F. A Revolução dos Idosos: o que muda no mundo com o aumento da população mais velha. Rio de Janeiro: Editora Elsevier, 2005.

TÓTORA, S. Ética da vida e o envelhecimento. In: CÔRTE, B.; MERCADANTE, E. F. Envelhecimento e velhice: um guia para a vida. Campinas: Vetor, 2006.

URQUIZA, A. et al. Sexualidad em la tercera edad: la imagen de los jóvenes universitários. Ponto e Vírgula, v. 4, p. 358-374, 2008.

\section{Como referenciar este artigo}

MONTEIRO, Solange Aparecida de Souza. Ciclos de vida e ética do envelhecimento. Temas em Educ. e Saúde, Araraquara, v. 14, n. 2, p. 254-267, jul./dez., 2018. e-ISSN 2526-3471. DOI: $10.26673 /$ tes.v14i2.12032

Submetido em: 03/06/2018

Revisões requeridas: 18/09/2018

Aprovado em: 19/10/2018 